\title{
ABORDAGEM ESP NA EDUCAÇÃO PROFISSIONAL: A FORMAÇÃO DOCENTE NO CONTEXTO PARANAENSE
}

\author{
ABORDAJE ESP EN LA EDUCACIÓN PROFESIONAL: LA FORMACIÓN \\ DOCENTE EN EL CONTEXTO PARANAENSE
}

\section{ESP APPROACH IN PROFESSIONAL EDUCATION: TEACHER EDUCATION IN PARANA STATE CONTEXT}

\author{
Vanessa SPINELO HEYDT ${ }^{1}$ \\ Rosemary Irene CASTAÑEDA ZANETTE ${ }^{2}$
}

RESUMO: A crescente especialização das áreas do conhecimento e o papel do inglês como língua franca evidenciam os estudos sobre o English for Specific Purposes (ESP). No contexto paranaense, uma das ofertas do ensino de ESP ocorre nos cursos técnicos da Educação Profissional ofertados pela Secretaria de Estado da Educação (SEED). Nesse contexto, alguns desafios enfrentados pelos docentes de Língua Inglesa com relação ao ensino do ESP são observadas e, dentre outros fatores, tais impasses podem estar relacionados à deficitária formação inicial dos professores. Dessa forma, objetivou-se, neste texto qualitativo e inserido no campo da Linguística Aplicada, verificar qual o tratamento dado a esse assunto nos currículos dos cursos de Letras de algumas universidades do estado do Paraná, por meio da análise da matriz curricular e das ementas de tais cursos. O referencial teórico apoiou-se, entre outros, em Celani (2009), Enterría Sánchez (2009) e Vian Junior (2015).

PALAVRAS-CHAVE: ESP. Formação docente. Cursos técnicos.

RESUMEN: La creciente especialización de las áreas del conocimiento y el papel del inglés como lengua franca evidencian los estudios sobre el English for Specific Purposes (ESP). En el contexto paranaense, una de las ofertas de enseñanza de ESP ocurre en los cursos técnicos de la Educación Profesional ofertados por la Secretaría de Estado de la Educación (SEED). En este contexto, algunos desafíos enfrentados por los docentes de Lengua Inglesa con relación a la enseñanza del ESP son observados y, entre otros factores, tales impases pueden estar relacionados a la deficitaria formación inicial de los profesores. De esta forma, se pretendió, en este texto cualitativo e insertado en el campo de la Lingüística Aplicada, verificar cuál el tratamiento dado a ese asunto en los currículos de los cursos de Letras de algunas universidades del estado de Paraná, por medio del análisis de la malla curricular y de la descripción de las asignaturas de tales cursos. El referencial teórico se apoyó, entre otros, en Celani (2009), Enterría Sánchez (2009) y Vian Junior (2015).

\footnotetext{
${ }^{1}$ Universidade Estadual do Oeste do Paraná (UNIOESTE), Cascavel - PR - Brasil. Mestranda em Letras. ORCID: <http://orcid.org/0000-0003-1769-200X>. E-mail: vanessa.spinelo@ gmail.com.

${ }^{2}$ Universidade Estadual do Oeste do Paraná (UNIOESTE), Cascavel - PR - Brasil. Professora Doutora do Departamento de Letras. ORCID: <http://orcid.org/0000-0002-0192-4702>. E-mail: roseitaliano@yahoo.it.
} 
PALABRAS CLAVE: ESP. Formación docente. Cursos técnicos.

ABSTRACT: The specialization expansion of the areas of knowledge, and the role of English as a lingua franca confirm the studies on English for Specific Purposes (ESP). In Paraná, the ESP is offered in technical courses of professional Education by the Parana State Secretary of Education (SEED). In this context, some challenges faced by English teachers in relation to ESP teaching are observed and, among other factors, such impasses may be related to the substandard initial teacher training. The aim of this qualitative text inserted in the field of Applied Linguistics was to verify the treatment given to this subject in the curricula of Language Arts in some universities of the state of Paraná, by means of the analysis of the curricular matrix and syllabus of such courses. The theoretical framework was based on studies of Celani (2009), Enterría Sánchez (2009), Vian Junior (2015), and others.

KEYWORDS: ESP. Teacher training. Technical courses.

\section{Introdução}

No Brasil, tem-se observado um crescimento na oferta e na procura por cursos de línguas para fins específicos (acadêmicos e profissionais) nos últimos anos. Isso se deve, especialmente, à abertura de fronteiras entre os países, à expansão tecnológica e à consequente dilatação das relações internacionais em diferentes contextos. Tais mudanças são refletidas no ensino, que precisa atender às especificidades das demandas contemporâneas.

O interesse pelo Ensino de Línguas para Fins Específicos (ELFE, doravante), mais especificamente o Inglês para Fins Específicos - English for Specific Purposes (ESP, de ora em diante) como objeto de estudo, não é recente. Esse assunto tem ganhado cada vez mais a atenção de pesquisas no âmbito acadêmico e possibilita profícuas reflexões sobre o ensino de língua estrangeira nos diferentes contextos específicos. Tendo em vista que a especialização das áreas do conhecimento é crescente, o ensino de línguas precisa acompanhar tal demanda.

Especificamente no Paraná, segundo as Diretrizes da Educação Profissional (PARANÁ, 2006), o estado iniciou, em 2004, uma expansão na oferta de cursos técnicos e uma reestruturação da Educação Profissional a partir da revogação do Decreto n. 2.208/97 e da promulgação do Decreto n. 5.15 4/04. Assim, nesse estado, uma das necessidades do ensino da língua inglesa para fins específicos ocorre nos 
cursos técnicos ofertados pela Secretaria de Estado da Educação (SEED), já que o inglês é a língua estrangeira presente na matriz curricular da maior parte dos cursos.

Diante desse contexto, a motivação para o presente estudo surgiu a partir de uma constatação a respeito das dificuldades enfrentadas por professores que atuam na Educação Profissional diante da necessidade de ensinar a Língua Inglesa (LI) nos cursos técnicos integrados e subsequentes nas escolas públicas do Paraná. Consequentemente, esse impasse pode estar relacionado à formação docente parcial ofertada por algumas universidades paranaenses, que deixam de contemplar em suas grades curriculares as questões referentes ao ensino de ESP.

Partindo desse lócus de pesquisa, o objetivo deste artigo foi verificar qual o tratamento dado ao ensino da LI para fins específicos nos currículos dos cursos de licenciatura em Letras de nove universidades públicas do estado do Paraná. Para isso, analisaram-se a matriz curricular e as ementas de tais cursos, que estão disponíveis na internet. Portanto, as informações divulgadas foram obtidas por meio de consulta aos endereços eletrônicos de cada uma das instituições, em dezembro de 2017.

Para atender ao proposto, este texto foi organizado da seguinte forma: primeiramente, foram apresentados o conceito e as origens do ESP. Na sequência, refletiu-se sobre como essa abordagem de ensino é retratada referente à formação inicial dos professores nos cursos de graduação. Posteriormente, tratou-se de modo mais específico sobre a abordagem do ESP no Paraná e seu contexto de ensino nas universidades e na Educação Profissional. Finalmente, conclui-se com a análise dos dados e as considerações sobre a importância da presença da abordagem ESP nos currículos acadêmicos.

\section{ESP: origens e aplicações}

A especialização das áreas do conhecimento, que vem sendo gradualmente potencializada por influência do mundo globalizado, e o papel do inglês como língua da no cenário mundial evidenciam os estudos sobre o ESP na atualidade. Hutchinson e Waters (1987), que foram uns dos precursores desses estudos, afirmam que o ESP surgiu em 1945, após o final da Segunda Guerra Mundial, quando se iniciou uma ampla expansão científica, tecnológica e econômica. Nesse cenário, os Estados Unidos se 
tornavam potência e o inglês tomava seu espaço como língua da comunicação internacional.

Para os mesmos autores, a abordagem do ESP está subdividida em três categorias: English for Science and Technology - EST (Inglês para Ciência e Tecnologia), English for Business and Economics - EBE (Inglês para Negócios e Economia) e English for Social Sciences - ESS (Inglês para as Ciências Sociais). Os autores ainda explicam que cada uma dessas ramificações ainda pode servir para fins acadêmicos (English for Academic Purposes - EAP) ou profissionais (English for Occupational Purposes - EOP).

Segundo Guimarães (2014), o ELFE, como o próprio nome sugere, é direcionado ao ensino de línguas (materna ou estrangeira) para uso em situações específicas de comunicação. De acordo com a mesma autora, o que diferencia um curso para fins específicos de um curso para fins gerais são os seus objetivos. No primeiro caso, as necessidades dos estudantes são previamente delimitadas, ou seja, desejam aprender particularidades da língua que possam ser aplicadas em contextos específicos de trabalho, de estudo, entre outros; já no segundo caso, o interesse do aluno é aprender a língua em um aspecto mais amplo.

Conforme Taglieber (1988), até o final da década de 40, o principal objetivo do ensino de línguas estrangeiras era a leitura, já que o método de gramática-tradução priorizava a compreensão de grandes obras na língua-alvo. Com o passar do tempo e a partir da necessidade de comunicação na língua universal - o inglês -, houve também uma mudança de perspectivas de estudo de língua estrangeira, isto é, novas concepções metodológicas de ensino foram surgindo. Borges (2003) aponta que, além da descrição das regras gramaticais da língua-alvo, também se passou a investigar a forma como essa língua era realmente usada para a comunicação nos diversos contextos. Dessa forma, os primeiros cursos de inglês para fins específicos começavam a surgir.

Em um contexto internacional, o Ensino de Inglês para Fins Específicos surgiu como disciplina oficial em universidades e escolas de inglês a partir da década de 60, mais precisamente em 1962, com a publicação do artigo "Some measurable characteristics of modern scientific prose”, de Barber (SWALES, 1985).

No Brasil, o Ensino de Inglês para Fins Específicos começou a ganhar espaço a partir de 1970 quando Maria Antonieta Celani iniciou um projeto em âmbito nacional: Projeto Nacional de Ensino de Inglês Instrumental. Segundo a pesquisadora, havia, no cenário acadêmico brasileiro, a necessidade de leitura e de compreensão de textos 
científicos publicados em LI, por isso a motivação para que o Projeto fosse posto em prática. Naquele contexto de ensino, a leitura e a compreensão de textos acadêmicos eram mais importantes do que a produção e a compreensão oral, o que contribuiu para que o Inglês Instrumental passasse a ser visto somente como inglês para leitura. A fim de colaborar para que outras habilidades linguísticas, como a produção escrita e a produção e compreensão oral, passassem a ser consideradas nessa abordagem de ensino de inglês para fins específicos, Celani propôs uma mudança na nomenclatura utilizada até aquele momento: "Projeto Nacional Ensino de Inglês Instrumental em Universidades Brasileiras (de agora em diante Projeto ESP) [...]" (CELANI, 2009, p. 17).

Ainda para a autora supracitada, o Projeto propiciou a mudança de uma visão na qual as necessidades dos alunos eram definidas somente por livros didáticos e não pelo contexto real das necessidades dos aprendizes. Hoje, o ensino-aprendizagem de ESP, muitas vezes ainda conhecido no Brasil como Inglês Instrumental, pode ser realizado por meio de uma das quatro habilidades comunicativas da língua, "que pode ser compreensão oral, produção oral, compreensão escrita e produção escrita, ou mesmo uma combinação entre elas, e a área de interesse do aluno, que pode ser relativa [...]" (MONTEIRO, 2009, p. 27).

Assim, tendo em vista a crescente demanda do ensino de ESP na contemporaneidade, reflexões acerca da formação docente a respeito dessa abordagem se fazem necessárias. Tal reflexão localiza-se na seção subsequente.

\section{O perfil do professor de $E S P$ e a formação docente}

Segundo Vian Junior (2015), a literatura da área é unânime ao afirmar que o professor de ESP é um professor para fins gerais que se deparou com a necessidade de lecionar inglês para fins específicos. Para o mesmo autor, é inevitável a referência ao Projeto Nacional de Ensino de Inglês Instrumental quando o assunto é formação de professores, pois, naquela ocasião, a questão da formação do professor de ESP foi amplamente discutida. No entanto, fora desse contexto, o interesse de pesquisadores sobre o tema não é frequente.

De acordo com Hutchinson e Waters (1987), o professor de ESP tem muitos papéis e há importantes práticas que diferem a atuação do professor de inglês geral e a 
do professor de inglês para contextos especializados. Os autores citam a preferência de Swales (1985) pela expressão "ESP practitioner" do que "ESP teacher", pois, além das funções do dia a dia de um professor, o profissional de ESP ainda terá que lidar com a análise de necessidades pontuais dos alunos, com o cronograma do curso, com a elaboração ou com a adaptação de material didático e avaliação. Outra questão tratada pelos autores é relacionada à formação, pois o "profissional de ESP", na maioria das vezes, não recebe a devida preparação no tocante ao ensino para fins específicos. Ele terá, portanto, de encontrar formas de lidar com uma nova realidade de ensino para a qual, na maioria das vezes, está despreparado.

Vian Junior (2015), ao citar Robinson (1991), menciona que para esse autor a flexibilidade é a principal qualidade do profissional de ESP; além disso, Vian Junior (2015) cita Dudley-Evans e St. John (1988), os quais atribuem ao profissional de ESP papéis como os de planejadores de curso, colaboradores e avaliadores.

É possível notar, assim, as múltiplas funções atribuídas ao professor de línguas para fins específicos e os desafios que podem ser encontrados no decorrer do percurso. Como destacam Hutchinson e Waters, "Os professores de ESP são, muitas vezes, relutantes moradores de uma terra estranha e inexplorada" (HUTCHINSON; WATERS, 1987, p. 158, tradução nossa) ${ }^{3}$. Essa é a metáfora utilizada pelos autores ao mencionarem os dilemas que surgem no trabalho dos professores de ESP: a falta de padrão dos cursos, que dificulta o uso de guias didáticos pré-elaborados, os novos campos do conhecimento com os quais o professor precisa lidar e a mudança da condição do ensino da LI que passa a considerar especificidades.

$\mathrm{Na}$ realidade do ensino de inglês na Educação Profissional paranaense, por exemplo, o professor, muitas vezes, precisa atuar simultaneamente em mais de um curso técnico. Esse fato faz com que o profissional tenha de lidar com diferentes áreas do conhecimento ao mesmo tempo, dificultando, assim, a elaboração de materiais e a própria pesquisa necessária para a análise das necessidades dos estudantes.

Com relação ao tipo de conhecimento que é esperado dos professores de ESP, Hutchinson e Waters (1987) argumentam que esses profissionais não precisam aprender o assunto especializado, embora precisem estar interessados nele. Os autores citam três necessidades fundamentais: (i) comportamento positivo do professor com relação ao conteúdo do ESP; (ii) conhecimento dos princípios básicos do assunto sobre o qual

${ }^{3}$ ESP teachers are too often reluctant dwellers in a strange and uncharted land. 
lecionará; e (iii) consciência do conhecimento linguístico que o aluno já possui. A partir desse posicionamento será possível encontrar as estratégias adequadas para o ensino.

Acerca do ensino de línguas para fins específicos, Enterría Sánchez (2009a), ao refletir sobre o ensino e aprendizagem das línguas de especialidade, por exemplo, assevera que o aumento da demanda da aprendizagem das línguas profissionais está estreitamente relacionado ao conhecimento exigido, pelo mercado contemporâneo, para uma adequada comunicação no contexto profissional. Segundo a autora, esse é o tipo de conhecimento que somente pode ser ensinado pelo professor de línguas para fins específicos, portanto, esse profissional deve focar sua formação a partir de um processo prévio de imersão na língua de especialidade que irá ensinar.

Enterría Sánchez (2009b), em outra publicação, afirma que o perfil do professor das línguas de especialidade é o de um mediador linguístico dedicado ao ensino da língua. A autora defende uma formação docente de qualidade, ao afirmar que o professor deve ter um sólido conhecimento das línguas de especialidade com as quais trabalha e, ao mesmo tempo, ser capaz de fazer alguma incursão no âmbito ou na área de especialidade em que se situa a aprendizagem. Conforme a autora, ao conhecer a teoria de comunicação que guiará o processo de ensino-aprendizagem da língua-alvo, o professor estará sempre disposto a, por exemplo, utilizar as novas tecnologias direcionadas à busca de materiais autênticos para preparar suas aulas ou para orientar o processo de aprendizagem por meio da internet.

Na mesma obra, Enterría Sánchez (2009b) menciona que os estudantes das línguas de especialidade são, em sua maioria, profissionais adultos cujo tempo tem um valor econômico, pois é preciso levar em conta as suas diversas atividades pessoais e profissionais. Assim, o professor deve valorizar, acima de tudo, os princípios da rapidez e da eficácia que devem ser prioritários no processo de aprendizagem. A autora também chama a atenção para o fato de que

A metodologia adotada pelo professor para levar até a sala de aula o processo de ensino-aprendizagem será um elemento decisivo. Este, além de situar-se no enfoque adequado, deverá abordar a língua de especialidade desde a descrição e a reflexão do âmbito de especialização no qual a ciência ou a técnica propostas devem estar necessariamente imersas (ENTERRÍA SÁNCHEZ, 2009b, p. 104, tradução nossa $)^{4}$.

${ }^{4}$ La metodología que adopte el profesor para llevar hasta el aula el proceso de enseñanza-aprendizaje será un elemento decisivo. Éste, además de situarse en el enfoque adecuado, deberá abordar la lengua de 
Fica evidente que, para que o professor de ESP dê conta daquilo que é esperado de sua prática pedagógica, é necessária uma formação inicial que contemple as questões relacionadas ao ensino de línguas de especialidade. As próximas duas seções dedicamse à análise de como esse assunto é tratado no contexto universitário paranaense.

\section{ESP e o contexto de ensino paraense: o reflexo da formação acadêmica na}

\section{Educação Profissional}

A oferta de cursos de ELFE, no Brasil, acontece no ensino público e privado, seja na Educação Básica, no Ensino Superior ou nos cursos livres. Especificamente no estado do Paraná, uma das necessidades do ensino da língua inglesa para fins específicos ocorre nos cursos técnicos da Educação Básica e Profissional ofertados pela SEED.

Segundo informações disponibilizadas em seu endereço eletrônico ${ }^{5}$, a SEED, na modalidade de ensino profissional e tecnológica, oferta cursos técnicos nas formas integradas e/ou subsequentes. Os Cursos Técnicos Integrados ao Ensino Médio são destinados aos alunos que já concluíram o Ensino Fundamental e asseguram a formação tanto no Ensino Médio quanto na área técnica profissional, enquanto os Subsequentes são para os concluintes do Ensino Médio e contemplam somente as disciplinas específicas. Ao todo são 43 cursos profissionalizantes ofertados: Curso de Formação de Docentes; Curso Técnico em Administração; Curso Técnico em Agroindústria; Curso Técnico em Agropecuária; Curso Técnico em Alimentos; Curso Técnico em Biocombustíveis; Curso Técnico em Celulose e Papel; Curso Técnico em Comércio Exterior; Curso Técnico em Contabilidade; Curso Técnico em Cozinha; Curso Técnico em Cuidados de Idosos; Curso Técnico em Desenho da Construção Civil; Curso Técnico em Edificações; Curso Técnico em Eletroeletrônica; Curso Técnico em Eletromecânica; Curso Técnico em Eletrônica; Curso Técnico em Eletrotécnica; Curso Técnico em Enfermagem; Curso Técnico em Estética; Curso Técnico em Eventos; Curso Técnico em Farmácia; Curso Técnico em Florestas; Curso Técnico em

especialidad desde la descripción y la reflexión del ámbito de especialización en el que la ciencia o la técnica propuestas han de estar forzosamente inmersas.

5 SECRETARIA DA EDUCAÇÃO. Cursos técnicos integrados e subsequentes. Disponível em: <http://www.educacao.pr.gov.br/modules/conteudo/conteudo.php?conteudo=1250>. Acesso em: $13 \mathrm{dez}$. 2017. 
Hospedagem; Curso Técnico em Informática; Curso Técnico em Logística; Curso Técnico em Manutenção e Suporte em Informática; Curso Técnico em Mecânica; Curso Técnico em Mecatrônica; Curso Técnico em Meio Ambiente; Curso Técnico em Nutrição e Dietética; Curso Técnico em Paisagismo; Curso Técnico em Portos; Curso Técnico em Produção de Áudio e Vídeo; Curso Técnico em Prótese Dentária; Curso Técnico em Química; Curso Técnico em Recursos Humanos; Curso Técnico em Redes de Computadores; Curso Técnico em Saúde Bucal; Curso Técnico em Secretariado; Curso Técnico em Segurança do Trabalho; Curso Técnico em Transações Imobiliárias; Curso Técnico em Vendas e Curso Técnico em Vestuário (SECRETARIA DA EDUCAÇÃO, 2017).

Há indícios de que o ensino de inglês no ensino técnico não apresenta resultados satisfatórios. Em uma primeira investigação documental, Spinelo e Zanette (2017) examinaram os Planos de Trabalho Docente (PTD) de professores que lecionam para o curso Técnico em Informática na modalidade integrada, em diferentes cidades do Oeste e do Sudoeste do Paraná. Constatou-se, por meio dessas breves análises, a ausência de conteúdos específicos da área, ou seja, os PTDs contemplavam apenas conteúdos da língua geral. As autoras concluíram, portanto, que a abordagem ESP não tem sido considerada pelos professores na elaboração dos seus planos e, possivelmente, não são colocadas em prática na sala de aula.

Ao que parece, a falta de preparo, que causa o suposto insucesso no Ensino de Língua Inglesa para Fins Específicos nos cursos técnicos da Educação Profissional, está atrelada a dois fatores: formação docente deficitária e material didático inapropriado. Ao se tratar especificamente sobre o primeiro item, percebe-se que a falta de contato com referenciais teóricos a respeito do ESP é recorrente entre os professores de línguas estrangeiras que lecionam para as turmas dos cursos técnicos. De modo geral, isso decorre não somente da formação acadêmica, que ainda trata timidamente o tema, como também da omissão dos órgãos competentes na oferta de formação continuada ao longo da carreira do professor.

Considerando a hipótese de que as dificuldades didático-metodológicas dos professores na aplicação do ESP em sala de aula estão relacionadas também à falta de formação inicial (e continuada) sobre o tema, faz-se importante trazer à tona questões referentes aos cursos de Letras e às características da formação que esses cursos oferecem. 
Segundo Cristovão e Beato-Canato (2016), os cursos de Letras, no Brasil, surgiram na década de 20 e se consolidaram como cursos universitários na década de 30, quando surgiam as primeiras universidades brasileiras. Segundo as autoras, a formação do professor, na sua esfera didática-pedagógica, historicamente, não era prioridade para os cursos, pois o foco dos currículos sempre foi o Beletrismo, ou seja, o ensino das artes das belas-letras.

De acordo com Daher e Sant'Anna (2009), citadas por Cristovão e Beato-Canato (2016), o Decreto-Lei n.1.190/1939 passou a considerar os cursos de Letras como responsáveis pela preparação dos professores de línguas. Contudo, desde as primeiras décadas de existência, os cursos voltavam-se à formação de bacharéis, supervalorizavam os saberes acadêmicos (linguísticos ou literários) e não se preocupavam com o contexto prático do trabalho docente. Segundo as autoras, esse fato justifica que ainda hoje alguns cursos de Letras continuem a não considerar, de maneira apropriada, o preparo didático-pedagógico do professor.

Cristovão e Beato-Canato (2016) lembram ainda, ao citarem Daher e Sant'Anna (2009), que a Lei de Diretrizes e Bases de 1996 e outros pareceres e resoluções que foram aprovados a partir de 2001, direcionam os cursos de Letras para uma perspectiva de mudanças nas dicotomias entre educação e trabalho e teoria e prática, buscando estabelecer um diálogo entre elas. Contudo, embora o compromisso de mudança tenha sido assumido pelas universidades brasileiras, algumas persistem na adaptação dos antigos padrões e ainda não consideram a formação integral do professor.

A formação docente voltada para o ensino de línguas para fins específicos, por exemplo, em geral é pouco considerada nos currículos dos cursos de Letras do país. Celani (2012) afirma que apesar de o Projeto ter impactado positivamente nas questões teóricas e práticas que envolvem o ESP, a formação docente para esse fim continua quase inexistente. Cristovão e Beato-Canato (2016) também relatam a presença tímida do assunto ESP na formação de professores nas instituições às quais estão vinculadas.

Tendo em vista essas informações, faz-se relevante um levantamento de dados sobre a presença da abordagem ESP nos cursos de Letras em universidades públicas do Estado do Paraná, atualizando, desse modo, informações anteriormente apresentadas por Cristovão e Beato-Canato (2016).

\section{Análise dos dados}


Nesta seção, alguns dados qualitativos foram apresentados por meio de análises documentais da matriz curricular e de ementas dos cursos de Letras de algumas universidades públicas paranaenses, com o objetivo de averiguar a presença (ou não) de conteúdos relativos ao ESP. Ressalta-se que o intuito aqui não é vincular, de forma categórica, a universidade pública à atuação dos professores da Secretaria de Estado da Educação do Paraná, pois é evidente que as universidades (públicas e privadas) não têm a função de formar professores para os quadros da SEED apenas. Esse seria um viés reducionista do processo formativo. Reitera-se que neste breve estudo, o recorte selecionado para a análise é constituído pela matriz curricular e as ementas dos cursos de Letras de algumas universidades públicas paranaenses, entretanto, reconhece-se que os professores de Língua Inglesa das escolas públicas desse estado são formados tanto em universidades públicas, quanto em privadas.

As informações aqui detalhadas foram obtidas em dezembro de 2017 por meio de consulta online, já que os documentos estão disponíveis nos sites das universidades e, em caráter complementar, atualizam alguns dados já apresentados por Cristovão e Beato-Canato (2016). Tais dados divulgados pelas autoras possivelmente foram coletados em 2013.

Para a análise que compõe este trabalho, nove universidades estaduais públicas paranaenses foram selecionadas. Essas instituições ofertam na graduação o curso de Licenciatura em Letras - Habilitação em Português/Inglês e Literaturas ou o curso de Licenciatura em Letras - Habilitação em Inglês e Literaturas. São elas: (i) Universidade Estadual de Londrina (UEL) - campus de Londrina; (ii) Universidade Estadual de Maringá (UEM) - campus de Maringá; (iii) Universidade Estadual do Paraná (UNESPAR) - campi de Apucarana, de Campo Mourão e de Paranavaí; (iv) Universidade Estadual de Ponta Grossa (UEPG) - campus de Ponta Grossa; (v) Universidade Estadual do Centro-Oeste (UNICENTRO) - campi de Guarapuava e de Irati; (vi) Universidade Estadual do Norte do Paraná (UENP) - campi de Cornélio Procópio e de Jacarezinho; (vii) Universidade Estadual do Oeste do Paraná (UNIOESTE) - campi de Cascavel, de Foz do Iguaçu e de Marechal Cândido Rondon; (viii) Universidade Federal do Paraná (UFPR) - campus de Curitiba; (ix) Universidade Tecnológica Federal do Paraná (UTFPR) - campi de Curitiba e de Pato Branco. 
Das nove instituições investigadas, apenas três apresentam, na matriz curricular ou nas ementas, questões relacionadas ao ESP: UEL, UNESPAR (somente no campus de Apucarana) e UNICENTRO (somente no campus de Irati). A maior parte das universidades analisadas não contempla nenhum conteúdo relacionado ao ESP nos documentos analisados: UEM; UNESPAR (campus de Campo Mourão); UEPG; UNICENTRO (campus de Guarapuava); UENP (campi de Cornélio Procópio e de Jacarezinho); UNIOESTE (campi de Cascavel, de Foz do Iguaçu e de Marechal Cândido Rondon) e UFPR. Ainda há instituições que não disponibilizaram os documentos em seus endereços eletrônicos: UNESPAR (campi de Paranavaí e de União da Vitória) e UTFPR (campi de Curitiba e de Pato Branco).

$\mathrm{Na}$ Universidade Estadual de Londrina (UEL), a disciplina referente ao ESP, que tem carga-horária de 60 horas e é ofertada na $2^{\mathrm{a}}$ série da graduação, se chama: Leitura em língua inglesa: aspectos teóricos. A descrição de sua ementa é: Pesquisa em Leitura. Ensino de leitura. Abordagem instrumental. Leitura crítica. Compreensão, crítica e proposição de ações alternativas a condições de vulnerabilidade ambiental e Direitos Humanos em textos/materiais para ensino de LI (UEL, 2017) ${ }^{6}$. Na Universidade Estadual do Paraná (UNESPAR) - campus de Apucarana -, a disciplina se chama: Leitura em Língua Inglesa: aspectos teóricos e aplicados, e a descrição da ementa é: Aspectos teóricos. Pesquisa em leitura. Ensino de leitura. Abordagem instrumental. Leitura crítica (UNESPAR, 2017) ${ }^{7}$. Essa disciplina tem sua carga-horária de 60 horas e está presente na matriz curricular da $4^{\text {a }}$ série. Já na Universidade Estadual do Centro-Oeste (UNICENTRO) - campus de Irati -, a disciplina, que é ofertada na forma optativa, é: Língua Inglesa Instrumental I, e o texto descrito na ementa é: Desenvolvimento de técnicas de leitura, aquisição de vocabulário e gramática visando

${ }^{6}$ UEL - UNIVERSIDADE ESTADUAL DE LONDRINA. Organização curricular. Disponível em: $<$ http://www.uel.br/prograd/catalogo-

cursos/catalogo_2017/organizacao_curricular/letras_lingua_inglesa_vespertino.pdf $>$. Acesso em: $17 \mathrm{dez}$. 2017;

UEL - UNIVERSIDADE ESTADUAL DE LONDRINA. Ementas. Disponível em: <http://www.uel.br/prograd/catalogo-

cursos/catalogo_2017/ementas/letras_lingua_inglesa_vespertino.pdf>. Acesso em: 17 dez. 2017.

7 UNESPAR - UNIVERSIDADE ESTADUAL DO PARANÁ. Matriz curricular. Disponível em: 〈http://www.fecea.br/userfiles/MATRIZ\%20CURRICULAR(2).pdf>. Acesso em: 13 dez. 2017.

UNESPAR - UNIVERSIDADE ESTADUAL DO PARANÁ. Plano de ensino. Disponível em:<http://www.fecea.br/userfiles/Planos\%20de\%20ensino\%204a\%20Serie\%20Letras\%20Ingles.pdf $>$. Acesso em: 13 dez. 2017. 
a compreensão de diferentes tipos de textos, em nível básico (IRATI, 2017) ${ }^{8}$. A cargahorária da disciplina é de 68 horas e é ofertada na $3^{\text {a }}$ série da graduação.

É possível observar o pequeno número de instituições que considera em suas ementas e/ou disciplinas conteúdos referentes ao ESP (das nove universidades investigadas, apenas três). Verifica-se que uma delas apresenta em seu currículo uma disciplina específica referente ao inglês instrumental; porém, não é obrigatória. A ênfase nos nomes das outras duas disciplinas está na leitura em língua inglesa, e não no ESP em seu contexto amplo. Desse modo, observa-se que a "abordagem instrumental" é apenas um dos itens que compõem a descrição das ementas. Reitera-se, entretanto, que estas são informações coletadas por meio de consulta online aos endereços eletrônicos das universidades, uma vez que não se conhece o contexto institucional, a quantidade de alunos que se inscrevem nas disciplinas, e demais aspectos peculiares, como os planos de aula dos professores, por exemplo.

Nota-se também, que o fato de os documentos adotarem a expressão "inglês instrumental" em vez de "ESP" também revela um provável direcionamento voltado ao estudo da compreensão escrita, ao passo que deixam de considerar as outras três habilidades da língua: produção oral, compreensão oral e produção escrita. Levando em consideração as subdivisões de Hutchinson e Waters (1987), o foco da abordagem ESP nas universidades em pauta, ainda nos dias de hoje, parece servir especialmente aos propósitos acadêmicos (English for Academic Purposes - EAP), já que o estudo da língua para fins profissionais (English for Occupational Purposes - EOP) não está suficientemente claro nos documentos.

Percebe-se, portanto, que o foco do trabalho com o inglês para fins específicos, nos cursos de Letras das instituições paranaenses pesquisadas, permanece atrelado ao ensino da leitura, possivelmente enfatizando os conhecimentos necessários para o futuro ingresso do aluno de Letras na pós-graduação. Dessa forma, não priorizam a formação do graduando em todas as dimensões necessárias, visto que, em sua futura atuação profissional, terá de lidar com o ensino do inglês voltado para os mais diversos propósitos. Ao atuarem nos cursos da Educação Profissional ofertados pela SEED, por

${ }^{8}$ UNICENTRO - UNIVERSIDADE ESTADUAL DO CENTRO-OESTE. Currículo pleno. Disponível em: <http://www2.unicentro.br/proen/files/2016/12/Letras-I.pdf?x34126>. Acesso em: $13 \mathrm{dez} .2017$. UNICENTRO - UNIVERSIDADE ESTADUAL DO CENTRO-OESTE. Ementário das disciplinas do curso de Letras-Irati. Disponível em: <http://www2.unicentro.br/proen/files/2016/12/LETRAS-I2009.pdf?x34126>. Acesso em: 13 dez. 2017. 
exemplo, o ensino da compreensão e da produção oral seria especialmente relevante nos Cursos Técnicos em Secretariado, Comércio Exterior e Hospedagem, dentre outros.

A falta de formação específica para o trabalho com ESP no currículo acadêmico pode trazer consequências negativas para a prática pedagógica dos professores em sala de aula, pois, como já enfatizado, não são raras as vezes que esses profissionais se deparam com a necessidade de ensinar a língua em contextos especializados. Como mencionado anteriormente, no Paraná, por exemplo, há evidências de que a abordagem ESP é pouco levada em consideração no ensino da LI nos cursos técnicos ofertados na rede pública de ensino. Consequentemente, as especificidades das áreas não são devidamente consideradas no ensino de Inglês nos diferentes cursos. Tal fato, presumivelmente, está relacionado às lacunas deixadas na formação inicial desses profissionais.

Cristovão e Beato-Canato (2016), ao citarem Celani (2012), mencionam que essa pesquisadora argumenta sobre a falta de formação de professores para atuar no ensino de línguas para fins específicos. Para ela, a formação inicial do professor deve contemplar tanto a instrução para ensinar a língua geral como a instrução para trabalhar línguas com fins específicos. De acordo com Cristovão e Beato-Canato (2016), para Celani (2012),

O professor de línguas para fins específicos deve ser capaz de: analisar a situação; avaliar as dificuldades dos alunos; perceber as origens das necessidades; realizar levantamento prévio do que o aluno vai precisar e do que já sabe, de sua familiaridade com a área; estudar os discursos e gêneros necessários; encontrar materiais. Com todas essas tarefas, o professor poderá ter um papel mais ou menos importante dependendo da sua formação e compreensão do contexto (CRISTOVÃO; BEATO-CANATO, 2016, p. 60).

Com relação ao ensino de ESP nos cursos técnicos no Ensino Médio, Cristovão e Beato-Canato (2016) citam novamente Celani (2012), a qual sugere o trabalho com os gêneros textuais específicos ainda no período da graduação. A partir desse posicionamento, as autoras advogam que a formação inicial do professor de inglês deve contemplar abordagens de gêneros em sua exposição e intervenção de perspectivas teórico-metodológicas para que o futuro professor esteja preparado para agir na docência também em contextos de demanda de línguas para fins específicos, já que esta se apresenta cada vez mais relevante nos contextos de ensino contemporâneos. 
Pertinente a isto, as pesquisadoras ainda ressaltam a necessidade do conhecimento e compreensão da intertextualidade e interdiscursividade dos gêneros textuais nas diversas esferas comunicativas que fazem uso das linguagens especializadas. Para trabalhar nessa perspectiva, o professor precisa estar aberto a novos desafios, pois em seu contexto de ensino estarão presentes novas situações comunicativas que fazem parte da necessidade de aprendizagem dos seus alunos. Assim, os conhecimentos linguísticos dos professores serão somados aos conhecimentos e específicos dos aprendizes e o trabalho poderá ser colaborativo.

\section{Considerações Finais}

A partir da análise documental realizada nesta pesquisa, percebeu-se que há uma certa relação entre as dificuldades enfrentadas no ensino de inglês para fins específicos nos cursos técnicos do estado do Paraná e a formação inicial do professor que advêm das universidades públicas desse estado. As ementas das disciplinas dos cursos de graduação analisadas mostram que o ESP ainda está pouco presente nos currículos dessas universidades. Os dados revelam que mesmo as instituições que consideram essa abordagem tratam-na como "inglês instrumental" e deixam claro que o foco do ensino é a leitura. Desse modo, percebe-se a necessidade de um olhar mais amplo sobre o tema, de maneira que a formação universitária passe a considerar o fato de que o professor de inglês em pré-serviço também poderá auxiliar na formação de profissionais das mais variadas áreas. Para isso, o foco da abordagem ESP na graduação não deve ser somente a compreensão escrita, mas deve considerar também as demais habilidades.

Conclui-se, assim, que a ampliação das discussões a respeito do ESP é imprescindível no ensino superior, pois a necessidade de aplicação desse conhecimento já é recorrente nos contextos de ensino e vem aumentando gradativamente (a exemplo dos cursos técnicos integrados e subsequentes ofertados no estado do Paraná). É essencial, pois, que os currículos acadêmicos passem a considerar o ESP como disciplina específica em algum momento da graduação.

\section{REFERÊNCIAS}


BORGES, E. F. do V. Discernimento do Esteio Teórico nos PCN de Língua Estrangeira - Ensino Fundamental. Dissertação de Mestrado. Universidade Estadual de Campinas, 2003.

CELANI, M. A. A. 2012. A formação de professores na área de línguas para fins específicos no contexto do século XXI. II Congresso Nacional de Línguas para Fins Específicos; XXIV Seminário Nacional de Inglês Instrumental; XII Seminário Nacional de Línguas Instrumentais. Anais. FATEC, São Paulo, 26-28 set. 2012.

CELANI, M. A. A. Revivendo a aventura: desafios, encontros e desencontros In: CELANI, M. A. A.; FREIRE, Maximina M.; RAMOS, Rosinda de Castro Guerra. (Orgs.). A abordagem instrumental no Brasil: um projeto, seus percursos e seus desdobramentos. São Paulo: EDUC, 2009, p. 17-31.

CRISTOVÃO, V. L. P; BEATO-CANATO, A. P.M.. A formação de professores línguas para fins específicos com base em gêneros textuais. D.E.L.T.A, vol.1, n 32, p 45-74. Disponível em: http://www.scielo.br/pdf/delta/v32n1/0102-4450-delta-32-0100045.pdf. Acesso em: 06 maio 2017.

ENTERRÍA, J. G. de. El lugar que ocupan las lenguas de especialidad en la enseñanza y aprendizaje del español como lengua extranjera. Anais do XX Congreso Internacional de la Asociación para la Enseñanza del Español como Lengua Extranjera (ASELE). Espanha: Fundación Comillas, 2009ª . Disponível em: <http://cvc.cervantes.es/ensenanza/biblioteca_ele/asele/pdf/20/20_0041.pdf>. Acesso em: 03 dez. 2017.

ENTERRÍA, J. G. de. La formación del profesor de español con fines profesionales. In: ENTERRÍA, J. G. El español lengua de especialidad: enseñanza y aprendizaje. Madrid: Arco/Libros, S.L., 2009b, p. 103-124.

GUIMARÃES, R, M. O ensino de línguas para fins específicos (ELFE) no Brasil e no mundo: ontem e hoje. HELB, Ano 8, n 8 - 1/2014. Disponível em:

http://www.helb.org.br/index.php/revista-helb/ano-8-no-8-12014/227-o-ensino-delinguas-para-fins-especificos-elfe-no-brasil-e-no-mundo-ontem-e-hoje. Acesso em: 17 maio 2017.

HUTCHINSON, T.; WATERS, A. English for specific purposes. Cambridge: Cambridge University Press, 1987.

MONTEIRO, M. F. C. Representações de professores de inglês em serviço sobre a abordagem instrumental: um estudo de caso. 2009. Dissertação (Mestrado em Linguística) - Pontifícia Universidade Católica de São Paulo, São Paulo, 2009.

PARANÁ. Diretrizes da educação profissional: Fundamentos políticos e pedagógicos. Curitiba: 2006.

SPINELO H., V.; ZANETTE, R. C., 2017. O léxico especializado e a articulação entre os conteúdos nos Cursos Técnicos Integrados. Anais. XIII Seminário Nacional de Literatura, História e Memória e IV Congresso Internacional de Pesquisa em Letras no 
Contexto Latino-Americano (SLH); III Seminário Internacional e IV Congresso Nacional em Estudos da Linguagem (SNEL); III Seminário Internacional de Etnia, Diversidade e Formação; II Congresso Internacional de Leitura e Literatura infantil e juvenil da Rede Paranaense de Leitura. Cascavel, PR: Universidade Estadual do Oeste do Paraná, 2017.

SWALES, J. Episodes in ESP. Oxford: Pergamon Press, 1985.

TAGLIEBER, L. K. A leitura na língua estrangeira. In: BOHN, H. I.; VANDRESEN, P. (Orgs.) Tópicos de Linguística Aplicada: O Ensino de Línguas Estrangeiras. Florianópolis: Ed. da UFSC, 1988, p. 237-257.

VIAN JUNIOR, O. A formação inicial do professor de inglês para fins específicos. In: LIMA-LOPES, R. E. de; FISCHER, C. R.; GAZOTTI-VALIM, M. A. (Orgs.).

Perspectivas em Línguas para Fins Específicos: Festschrift para Rosinda Ramos. Campinas: Pontes, 2015, p. 187-208.

\section{Como referenciar este artigo}

SPINELO H, V.; ZANETTE, R. C.; Abordagem ESP na Educação Profissional: a formação docente no contexto paranaense. Rev. EntreLínguas, Araraquara, v. 4, n. 2 , p. 323-339, jul./dez., 2018. E-ISSN: 2447-3529. DOI: 10.29051/rel.unesp.v4.n2.2018.11980

Submetido em: 14/09/2018

Aprovado em: 10/10/2018 